\title{
Improved reliability in production of maize inbred lines by the combination of the R1-navajo marker with flow cytometry or microsatellite genotyping
}

\author{
F. Rádi ${ }^{1,2,4} \cdot$ K. Török ${ }^{1} \cdot$ M. Nagymihály ${ }^{3}$ A. Kereszt ${ }^{1,3} \cdot$ D. Dudits ${ }^{1}$
}

Received: 31 March 2020 / Accepted: 16 June 2020 / Published online: 23 June 2020

(c) The Author(s) 2020

\begin{abstract}
Doubled haploid (DH) technology is an essential component in producing inbred lines for a competitive maize (Zea mays L.) breeding program. The $R 1$-navajo $(R I-n j)$ gene provides phenotypic marker that insures only variable reliability for seed selection of haploid embryos. Therefore, in the present study we outline a complex protocol for early stage genome size determination that integrates the phenotypic screening with the flow cytometry of nuclei from root tips and with the use of DNA isolated from seedlings for molecular marker-based genotyping. In a representative experiment with three genotypes, only $59 \%$ of the color marker pre-selected seeds were confirmed to be haploid by cytometric analysis of nuclei isolated from root tips. As a novel tool we have identified the UMC1152 SSR marker being polymorphic between the haploid inducer line (K405) and the K4390 hybrid as parents to screen seedlings pre-selected with the R1-navajo marker. Using this molecular marker, alleles characteristic for the inducer K405 line could not be detected in 83\% of seedlings previously selected as haploid candidate. Seedlings identified as haploids were exposed to $0.06 \%$ colchicine solution for rediploidization. This procedure resulted in doubled haploids with $3 \%$ frequency relative to the initial population as it was quantified by the number of mature maize plants with fertile tassel. The described complex approach can support safer identification of haploids at early seedling stage in a hybrid population derived from crossing with a haploid inducer line.
\end{abstract}

Keywords Anthocyanin $\cdot$ Genome size $\cdot$ Single sequence repeat $\cdot$ Root $\cdot$ Colchicine $\cdot$ Doubled haploid

\section{Introduction}

The utilization of heterosis in hybrid maize (Zea mays L.) breeding has become a key component in improving yield, greater uniformity for machine harvesting, and increase yield stability under extreme abiotic stress. Hybrid performance depends on the inbreds being vital sources of beneficial alleles for development and improvement of competitive

\section{F. Rádi}

rferiz92@gmail.com

1 Institute of Plant Biology, Biological Research Centre, Temesvári krt. 62, Szeged, Hungary

2 Kiskun Research Center Ltd., Füzespuszta 42, Kiskunhalas, Hungary

3 ATGandCo Biotechnology Ltd., Kissori út 16, Mórahalom, Hungary

$4 \mathrm{PhD}$ School in Biology, University of Szeged, Középfasor 20, Szeged, Hungary maize hybrids. Inbreeding by repeated self-pollinations is a time consuming process requiring $8-10$ generations. Therefore, the in vivo doubled haploid (DH) technology has been adopted by increasing number of commercial maize breeding programs (see review by Chaikam et al. 2019).

There are two distinct phases in DH technology. During the first phase, generation of maternal haploid maize plants with single set of chromosomes can be achieved by crossing the source germplasm as the female parent with the haploid inducer as the male parent. Introduction of stock 6 line (Coe 1959) as the first invented haploid inducer yielded 2-3\% haploids (Zhang et al. 2008). Improvement of the haploid induction (HI) efficiency has been a primary goal and identification of several new and more efficient inducer lines have been reported as listed by $\mathrm{Yu}$ and Birchler (2016). Consequently, haploid induction methodologies have been improved significantly, the frequency can reach up to $20 \%$ of haploid seeds. The haploid induction rate (HIR) is under genetic control and the genome-wide association studies (GWAS) identified genomic regions required for 
HI expression (Hu et al. 2016). Under these circumstances, efficient and accurate identification of maize plants with reduced genome size is a key component in large scale production of inbred lines.

Haploid/diploid sorting can be based on various phenotypic markers. The anthocyanin color marker, Rl-nj (Navajo) is one of the most widely used in a variety of haploid inducer systems (Chaikam and Prasanna 2012; Chaikam and Mahuku 2012; Melchinger et al. 2013). The maternal haploid progenies show purple pigmentation in the endosperm tissue on the crown of the kernel and colorless embryos. The colorization of the aleuron indicates that the fertilization was successful with the inducer line (Chaikam et al. 2015). However, functionality of the $R I-n j$ marker can be limited due to the expression of dominant anthocyanin inhibitor genes like C1-I. If the maternal parent contains inhibitory alleles of the $\mathrm{C} 1$ anthocyanin regulatory locus or has originally colored scutella, or when the shape of the endosperm and the way it surrounds the scutella prohibit color determination, the clear identification of haploid seeds is difficult or impossible (Röber et al. 2005; Prigge et al. 2012). To overcome these limitations of the $R I-n j$ marker system, different approaches were tested. For example, differences in the oil content between haploid and diploid kernels can serve as molecular markers (Rotarenco et al. 2007; Melchinger et al. 2015) however, it requires specialized NMR equipment. Ambiguities of the existing systems could be minimized by using RWS inducer lines that express the green fluorescence protein (GFP), a dominant marker (Yu and Birchler 2016). In this approach, the germinated diploid seeds show GFP fluorescence in emerged radicles and coleoptiles, while haploids are GFP negative due to the elimination of the transgene. Triple anthocyanin color markers expressed in the seedling roots and leaf sheaths (Chaikam et al. 2016) and significant differences in seedling traits between diploids and haploids were also used as elements in an integrated screening system (Chaikam et al. 2017).

The DH technology requires additional methods to identify haploids accurately and efficiently in various maize germplasms. The most reliable method for selection of haploids is the chromosome counting after staining mitotic cells with a $1 \%$ solution of lacto-acetic orcein as it was done with tropical maize germplasms (Milani et al. 2016). In a maize genetic improvement program, there is a need for large scale identification of putative haploid with affordable cost. Identification of DNA content by flow cytometry may meet these requirements, especially if new technologies are developed. Alternatively, molecular markers, as microsatellites (simple sequence repeats: SSR) can confirm haploid or diploid nature of an offspring (Belicuas et al. 2007). Simultaneous use of these approaches was also reported in breeding of tropical maize (Battistelli et al. 2013). Identification of novel markers can support the extended use of this method in practical breeding. The second phase, in the production of inbreed lines includes the rediploidization of genome in order to restore the fertility of plants. Doubling of chromosome set can be achieved by treating the haploid seedlings with colchicine, anti-mitotic herbicides or nitrous oxide (see review by Chaikam et al. 2019). Colchicine treatment was successfully used for production of tetraploid maize variants (Novák-Hajós and Gyulavári 2013) as well as for treatment of maize anther cultures (Barnabás et al. 1999). In Hungary, there has been a long history of maize monoploid method's experiments. Gyulavári (1967) and Csetneki (1967) improved root markers and selected monoploid derived maize lines. Using root markers Gyulavári (1967) obtained 269 monoploids $(0.9 \%$ ) verified by cytological examination following root coloration selection from 292,638 seedlings in years between 1962 and 1966. This program resulted in 61 homozygous diploid genotypes. These lines showed stability in the later generations. Out of these lines 11 were tested in hybrid production program, and several of their hybrids exceeded the yield of the standard hybrids at that time.

In the present study, we provide quantitative data about reliability of an integrated system in which the RI-navajo $(R I-n j)$ marker was combined with genome size analysis and use of a single sequence repeat (SSR) marker, at early seedling stage for the identification of haploid progenies. The described frequency data from the use of Hungarian genetic stocks (Central European region) are comparable to the results of DH breeding programs with tropical maize germplasm.

\section{Materials and methods}

\section{Haploid induction crosses and color phenotyping}

The haploid induction nursery was established in Kiskunhalas at the southern part of the Great Hungarian Plain in 2015-2016. The late flowering (85 days vegetative growth phase) maize haploid inducer line K405 with RWS origin (Röber et al. 2005) was used as male parent in the crossing program with maternal plants from the early flowering K4390 and K4368 as well as the late flowering K4250 hybrids of different genetic backgrounds. These plant materials and the parental lines of the hybrids were kindly provided by the Kiskun Research Center Ltd. for our research. After maturation of seeds produced from the induction crosses, anthocyanin coloration was screened. Seeds having coloration in the endosperm but not in the embryo were considered as potential haploids, while seed producing anthocyanin in both endosperm and embryo were categorized as diploids/ hybrids. 


\section{Genome size screening with flow cytometry}

Ploidy levels of seedlings grown from the pre-selected seeds were determined by a flow cytometer (BD FACS Calibur) equipped with 532-nm green solid-state laser, operating at $30 \mathrm{~mW}$. Mature seeds with purple pigmentation in the endosperm tissue and colorless embryos were sterilized with $70 \%$ ethanol for $1 \mathrm{~min}$, rinsed in sterile water and treated with $2.5 \%[v / v]$ sodium hypochlorite for $30 \mathrm{~min}$. After washing in sterile water, the second sterilization was carried out with a $0.2 \%[w / v] \mathrm{HgCl}_{2}$ solution for $5 \mathrm{~min}$ that was followed by 5-6 times rinsing in sterile water. Seeds were germinated in dark at $24^{\circ} \mathrm{C}$ on wet filter paper. Nuclei extractions were done by chopping of root tips (approximately $5-10 \mathrm{~mm}$ in size) on ice with a razor blade in a $55 \mathrm{~mm}$ diameter Petri Dish containing $1 \mathrm{~mL}$ extraction buffer: $9.35 \mathrm{mM} \mathrm{MgSO} \cdot \cdot 7 \mathrm{H}_{2} \mathrm{O} ; 47.67 \mathrm{mM} \mathrm{KCl}$; 4.77 mM HEPES (4-(2-hydroxyethyl)-1-piperazineethanesulfonic acid), $6.48 \mathrm{mM}$ dithiothreitol (DTT), $0.25 \%[v / v]$ Triton X-100 (pH 8). This suspension was filtered through a $40 \mu \mathrm{m}$ nylon mesh and treated with a RNAse A solution $(100 \mu \mathrm{g} / \mathrm{mL})$ before staining with propidium iodide $1 \mu \mathrm{g} / \mathrm{mL}$ (Sigma) for $10 \mathrm{~min}$. At least 10,000 gated particles were analyzed per sample. Identical instrument settings were used in order to have comparable relative fluorescence intensity values. As diploid control samples, nuclei from the hybrid parents were isolated and analyzed in the same way. Histograms were obtained using the Cell Quest (BD Biosciences) program, and analyzed with the WinMDI 2.8 software 2009.

\section{DNA isolation and genotyping}

Genomic DNA was extracted using the MasterPure ${ }^{\mathrm{TM}}$ Complete DNA and RNA Purification Kit (Epicentre, USA). 10 ng template DNA were used in the PCR reactions. The $20 \mu \mathrm{L}$ reaction contained $0.25 \mu \mathrm{M}$ of primers, $0.25 \mathrm{mM}$ of each dNTPs, $2.5 \mathrm{mM} \mathrm{MgCl}_{2}$ and $0.75 \mathrm{U} \mathrm{Go}^{\circledR} \mathrm{Taq}$ G2 Flexi DNA Polymerase (Promega, USA). The PCR reactions were performed in a Veriti Thermal Cycler (ThermoFisher Scientific, USA) as follows: denaturation for $2 \mathrm{~min}$ at $95^{\circ} \mathrm{C}$, followed by 35 cycles of $95^{\circ} \mathrm{C}$ for $30 \mathrm{~s}, 60^{\circ} \mathrm{C}$ for $30 \mathrm{~s}, 72^{\circ} \mathrm{C}$ for $30 \mathrm{~s}$ and final extension for $5 \mathrm{~min}$ at $72^{\circ} \mathrm{C}$. The sequence of oligonucleotide primers to amplify the UMC1152 SSR marker is described by Shehata et al. (2009). The PCR products $(3 \mu \mathrm{L})$ were mixed with $2 x$ TBE-Urea Sample Buffer (Invitrogen, USA) and loaded onto denaturing 10\% TBEUrea Gels (Invitrogen, USA). DNA samples were electrophoresed in 1xTBE Buffer ( $\mathrm{pH} 8.3$ ) at $180 \mathrm{~V}$ for 3.5-4 h using the GeneRuler 50 bp DNA ladder (Thermo Fisher Scientific) as size control. Finally, DNA bands were visualized using SYBR Safe DNA Gel Stain (Invitrogen, USA).

\section{Growing fertile double haploids from colchicine-treated haploid seedlings}

Chromosome doubling was performed according to Chase and Nanda (1956) with a few modifications. The germinated haploid kernels with about $3-5 \mathrm{~cm}$ long coleoptiles were cut open vertically and submerged into $0.1 \%$ colchicine solution with $0.1 \%$ DMSO, and $0.1 \%$ Tween 20 for $6 \mathrm{~h}$ in dark at $22{ }^{\circ} \mathrm{C}$ temperature. These colchicine-treated seedlings were washed in tap water 3 times, and planted in Styrofoam trays containing peat moss and cultured in a growth chamber with $16 \mathrm{~h} \mathrm{light} / 8 \mathrm{~h}$ dark at $28{ }^{\circ} \mathrm{C}$ up to $4-5$ leaf stage. The outgrowing plants were then transferred to the field. Plants with well-developed ear and tassel were self-pollinated, and the seed setting indicated the functionality of both sex organs and the doubled haploid nature of progenies.

\section{Results}

\section{Crossing program with inducer line carrying the $R 1$-navajo (R1-nj) marker and phenotypic screen of seeds}

In the present in vivo experiments, haploid induction was achieved by crossing the source germplasms represented by three hybrids (K4390, K4368, K4250) with pollens from the K405 haploid inducer with RWS origin having the $R I-n j$ gene as a marker for screening the seeds for genome size of embryos (Röber et al. 2005). After pollination of 5 cobs of K4390, K4368 and K4250 hybrids each with the K405 haploid inducer, both low and high expression of pigmentation was detected in the seeds of progenies (Fig. 1a). A total of 2280 of seeds from the three segregating populations were screened for anthocyanin colorization. Grains with purple endosperm and white embryos were separated as described by Chase and Nanda (1956). This phenotypic screen identified 399 seeds as putative haploid progenies emerged by the elimination of paternal chromosomes from embryos. Thus, $17.5 \%$ of the seeds were putatively haploid with a variation from 12.0 to $25.0 \%$ in the three populations. Representative kernels with characteristic color markers shown in Fig. 1b, $\mathrm{c}, \mathrm{d}$ can highlight uncertainties in the visual screening of dry seed pigmentation. Therefore, alternative methods were tested to confirm the ploidy level of seedlings.

\section{Flow cytometric genome size determination in roots developed from marker pre-selected kernels}

To confirm the true ploidy status of tentative haploid seedlings we adapted protocols for nuclei isolation from root tips and for reliable determination of genome size with flow cytometry (Dudits et al. 2016). Figure 2 shows representative 


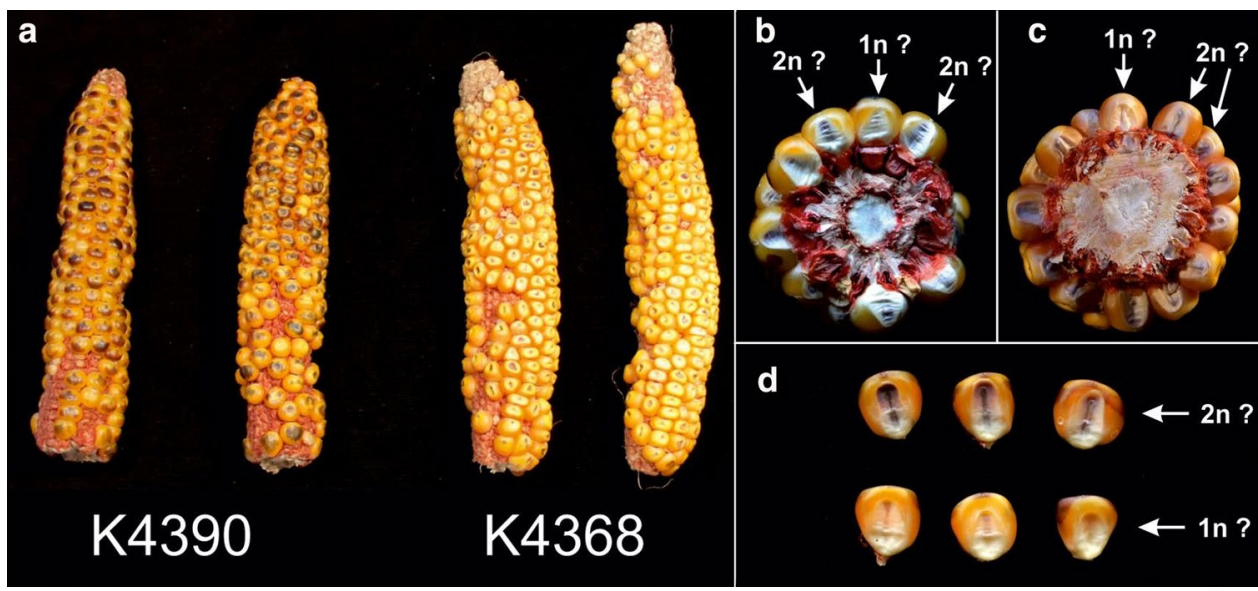

Fig. 1 Manifestation of the $R l-n j$ marker. Genotype of the maternal parent modifies the expression of anthocyanin pigmentation after crossing with haploid inducer plants. a Different $R 1-n j$ gene expression in two hybrid combinations shows segregation of kernels with strong (K4390) and weak (K4368) Rl-nj phenotype. A close-up

histograms of flow cytometric analysis of haploid (Fig. 2b, c, d), diploid (Fig. 2e) and mixoploid (Fig. 2f) maize seedlings. Estimation of nuclear DNA content of each sample was performed by comparing the position of its G1 peak to that of nuclei from a commercial hybrid (Fig. 2a). We found root samples with both haploid and diploid nuclei which indicate the mixoploid nature of analyzed progeny (Fig. 2f).

Quantitative genome size data from flow cytometric analyses revealed high frequency of false positives, i.e., diploid or mixoploid embryos categorized as haploids, during the color marker-based pre-selection. The counted number of true haploids was 237 seeds that correspond to $59.4 \%$ of the primarily pre-selected population and $10.4 \%$ of the total seed number. The early elimination of the identified 162 diploid/mixoploid progenies (with the average of $40.6 \%$ ranging from 35.8 to $57.8 \%$ ) can significantly increase the productivity of the whole inbred line production program. One can expect essential cost reduction by application of this protocol before subsequent steps as diploidization and field growing the colchicine-treated plants.

Screening for oil content, fluorescence, or ploidy level requires expensive equipment, which are usually not available for small breeding companies. In contrast, DNA-based molecular markers are easy and cheap of use. That is why, a polymerase chain reaction (PCR)-based screening technique was evaluated. Microsatellites or SSRs are codominant markers, i.e., the presence of both parental alleles can be detected in case they are different in length. This type of markers can be present in maize breeding populations with as high as over 20 alleles (Senior et al. 1998). We have selected the UMC1152 marker that was polymorphic between the haploid inducer line K405 and the parental lines of the K4390 hybrid. Figure 3 shows the UMC1152 of b K4390 and c K4368 derived kernels obtained after crossing the hybrids with K405. d $R 1-n j$ phenotypes in the crown region of endosperms and in the embryos. The putative haploid (1n) and diploid $(2 n)$ seeds are indicated

polimorphism between K405 and the parents of K4390 and the genotype of 12 haploid candidates prescreened for the presence of the "Red crown" (R1-nj) marker. All but two haploid candidates carry UMC1152 alleles only from the K4390 hybrid, while those alleles were eliminated from an albino plantlet (number 10) and the K405 allele was retained. A false positive candidate (number 12) proved to be diploid (or mixoploid) and carries both K405 and K4390 alleles.

\section{Diploidization of shoot meristems by colchicine treatment}

In the present study, only the 237 true haploid seedlings were used for diploidization. Evaluation of the efficiency of the duplication protocol by flow cytometry showed the highest $(69.33 \%)$ rate of duplicated plants when the roots were immersed into $0.1 \%$ colchicine solution, $0.1 \%$ DMSO, and $0.1 \%$ Tween 20 for $6 \mathrm{~h}$ in dark at $22{ }^{\circ} \mathrm{C}$ temperature (De Oliveira Couto et al. 2015). The described protocol allowed the treatment of all seedlings from the significantly reduced haploid plant population with colchicine solution. These plantlets were first grown under greenhouse conditions and were transferred to the field after reaching the height of 15-20 cm (Fig. 4). Instead of this approach, the proposed strategy monitors tassel fertility estimating the number of plants that produce pollen and self-fertilized seeds (Fig. 5). This analysis indicated that the applied colchicine treatment protocol resulted in diploid fertile maize plants with $36.7 \%$ of the pre-selected true haploids. If the analysis is conducted on a total number of seeds from crossings with inducer lines, the combined efficiency of double haploid production is $3 \%$ of the 2280 progenies. 
Fig. 2 Determination of the ploidy level of individual progenies by flow cytometric analysis of relative DNA content in nuclei isolated from roots of putative haploid seedlings. a Relative DNA content profile of a commercial hybrid. Representative histograms are shown for haploid (b, c, d), diploid (e), and mixoploid (f) maize seedlings
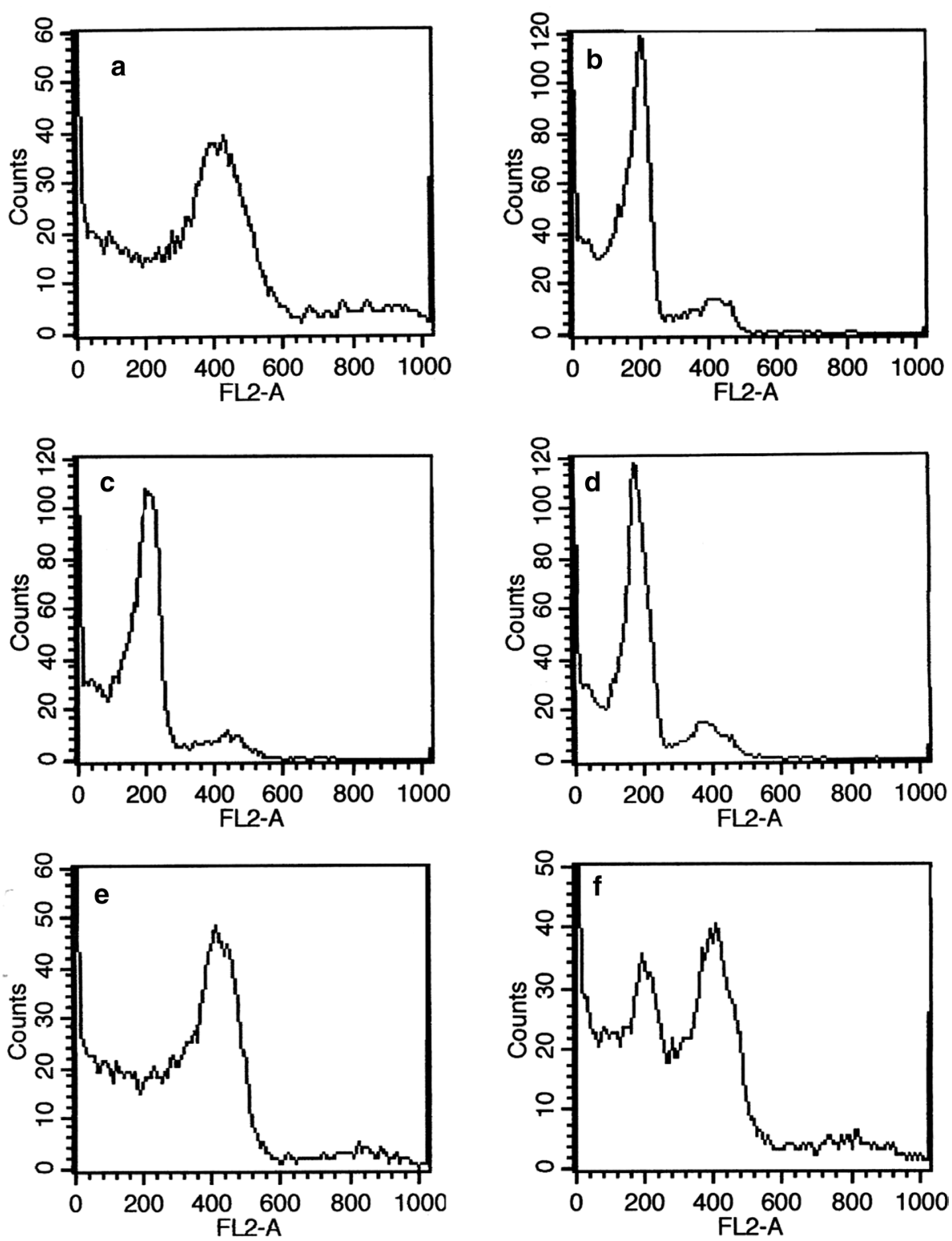

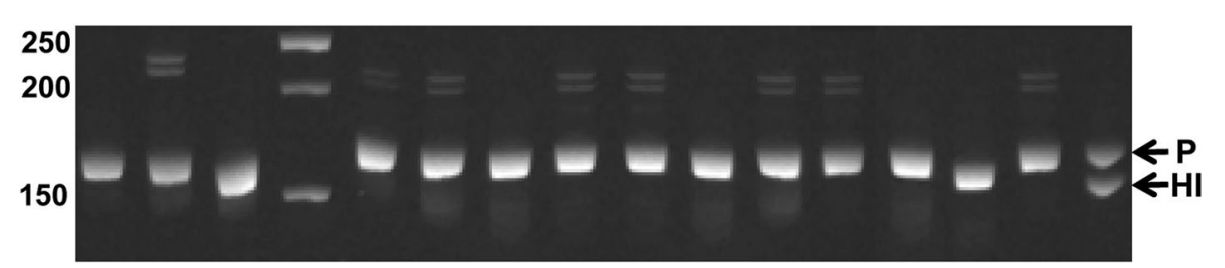

Fig. 3 Genotyping of the parental lines (P1, P2) of the K4390 hybrid, the haploid inducer (HI) K405 line and 12 haploid candidates obtained after crossing K4390 and K405 with the UMC1152 SSR marker. The size of three fragments of the GeneRuler $50 \mathrm{bp}$

In agreement with the previous reports on doubled haploid breeding programs with tropical maize germplasm, the present study using Central European breeding stocks
DNA ladder (M) are shown in left, while the DNA fragments from the parental lines $(\mathrm{P})$ and the haploid inducer $(\mathrm{HI})$ are indicated by arrows on the right

emphasizes the potentials in pre-selection of true haploids by combined use of the R1-navajo (RI-nj) marker system and genome size quantification with flow cytometry and/ 
Fig. 4 Various stages in growing doubled haploid maize plants. Seedling after colchicine treatment (a), potential doubled haploid plant transferred to the field (b). Flowering doubled haploid plant (c)

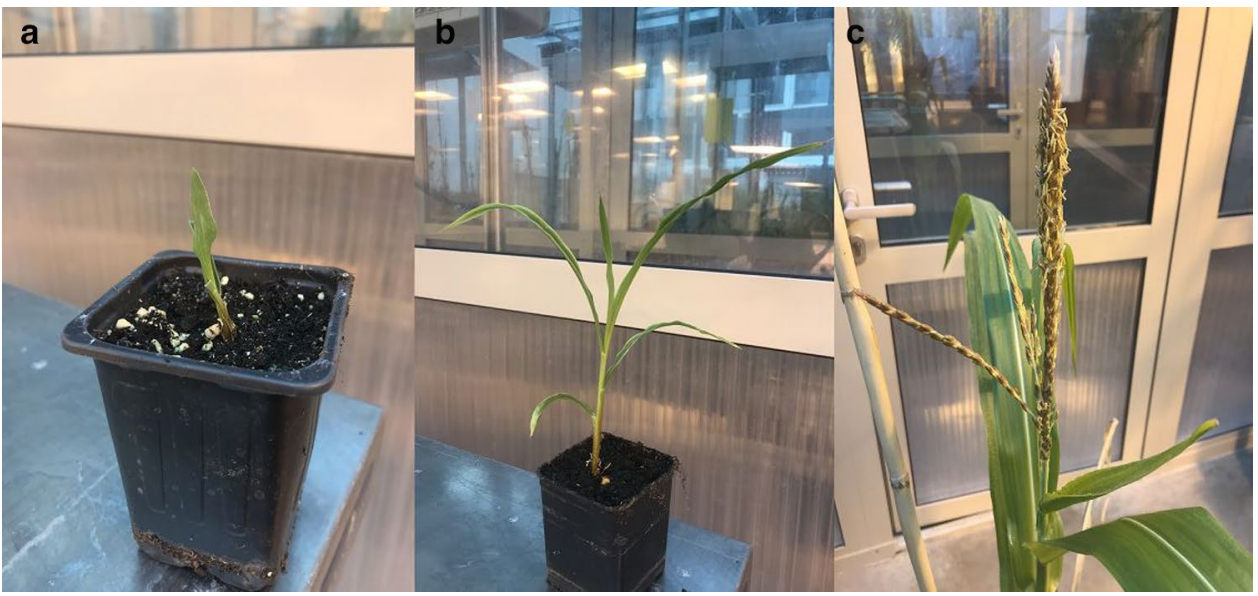

Fig. 5 Self pollinated cobs of fertile doubled haploid plants

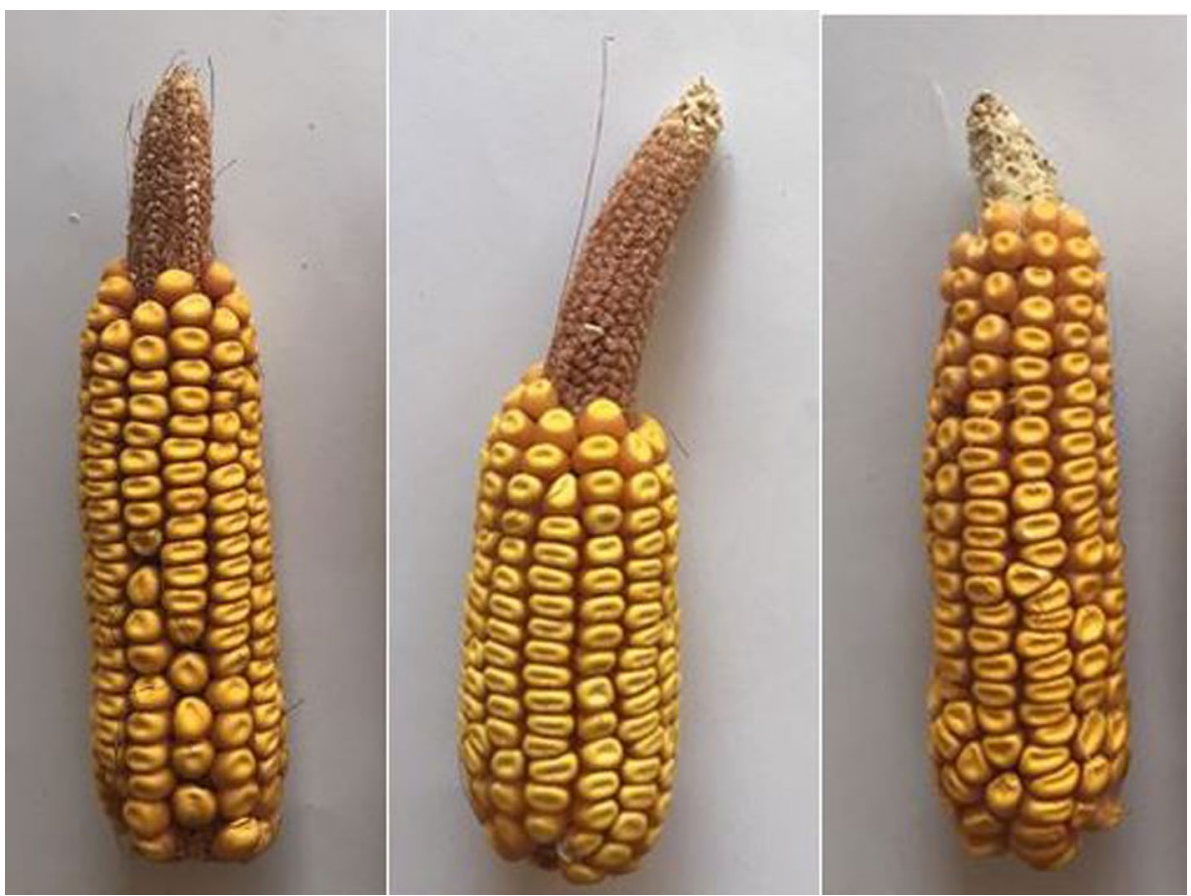

or simple PCR-based SSR genotyping during early seedling stage. The summary chart (Fig. 6) presents efficiency data at various steps of maize inbred line generation. The described protocol shifts the use of flow cytometry from the post-diploidization phase to the root analysis of the putative haploid seedlings germinated from the kernels selected visually after in vivo haploid induction.

\section{Discussion}

Maize (Zea mays L.) is one of the most important annual cereal crops in the world, and productivity of leading hybrids is largely dependent on the hybrid heterosis. The hybrid vigor is under the control of combinatory interaction between inbred parents. Therefore, efficient production of inbred lines is a basic requirement in a successful breeding program. In the last two to three decades, in vivo doubled haploid (DH) technology has emerged as an efficient alternative to the traditional method of inbred line development that is used also in Hungarian maize breeding programs. The aim is to produce completely homozygous lines that includes two basic steps. First production of genetic stocks with reduced chromosome number $(2 n=10)$ that is followed by doubling haploid genomes. In the present work we show that the K405 haploid inducer line with RWS origin having the $R I-n j$ gene as a marker can serve as pre-screening seed progenies. Our findings that the genetic background of the maternal parents indeed influences the functionality of the marker gene was observed earlier (Prigge et al. 2012). We can find data 
Fig. 6 Summary chart presents the efficiencies at the different stages of doubled haploid production system based on the two component selection with the Rl-navajo (Rl-nj) marker system and flow cytometry
Total number of analized

\section{kernels}

2280

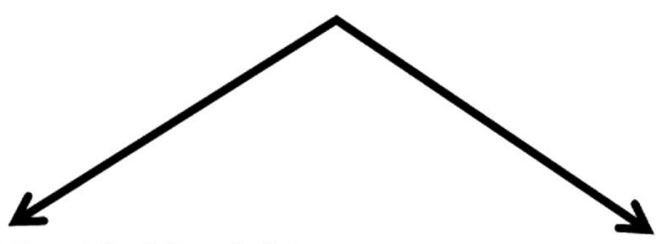

Seed marker identified haploids

399

Seed marker identified diploids

1881

$17 \%$

$83 \%$

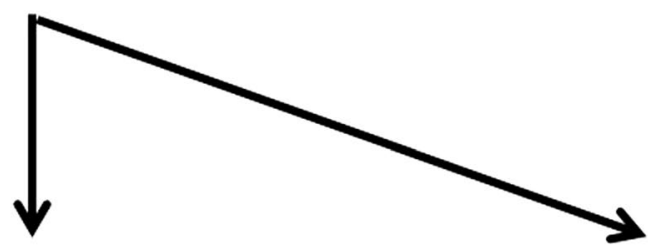

Flow cytometry identified haploids Flow cytometry identified diploids

237

162

$10 \%$

$7 \%$

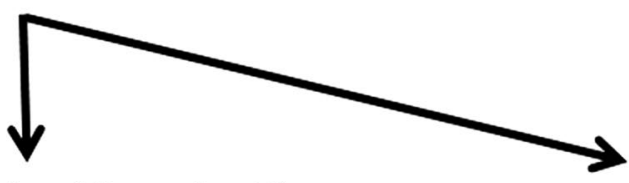

Doubled haploids with seed setting after colchicine treatment

Sterile plants after colchicine treatment

87

150

$3 \%$

$7 \%$ about the observation of an error rate of $33.5 \%$ revealed by genome size analysis following the Rl-Navajo marker selection, which is comparable to our data of $40.6 \%$. This limitation encourages the use of additional techniques for identification of haploid seedlings. Here, we introduced two additional methods as flow cytometry and simple sequence repeats (SSR) marker-based genotyping. We extend the combinatory use of these techniques in a Hungarian maize breeding program.

In the present work, the haploid induction rate ranged between 4.1 and $32.1 \%$, similar efficiencies were published for six tropical hybrids after crossing with Krasnodar Embryo Marker Synthetic (KEMS) inducer line (Battistelli et al. 2013). Application of genome size determination with flow cytometry has already been used in different in vivo haploid induction projects but mainly for characterization of plants after diploidization. In those studies, nuclei were isolated from leaves of colchicinetreated plants (Battistelli et al. 2013; De Oliveira Couto et al. 2015). Flow cytometric analyses revealed the occurrence of mixoploid embryos in our plant populations. This finding is in accordance with the detection of mixoploid embryos in a study on selective elimination of uniparental chromosomes during haploid induction mechanisms (Zhao et al. 2013). Colchicine treatment of maize seedlings is the most frequently applied method for doubling chromosome sets (Battistelli et al. 2013; Choe et al. 2012; Dang et al. 2012). We applied this methodology that resulted in diploid fertile maize plants with $36.7 \%$ of the pre-selected true haploids.

Despite of the fact that the described protocol could be used there is a need to increase the efficiency of in vivo haploid induction. Discovery of new inducer lines can be a key in these attempts (Chaikam et al. 2019).

Acknowledgements : Open access funding provided by ELKH Biological Research Center. This project was supported by the Ministry of National Economy (Hungary), Grant Number: GINOP-2.1.1-15-2015-00092.

Author's contribution FR: field experiments, crossing, colchicine treatment, statistical analysis, KT: flow cytometry, MN: UMC1152 marker 
generation, AK: genomic hybridization, monitoring genome elimination, DD: manuscript preparation.

Open Access This article is licensed under a Creative Commons Attribution 4.0 International License, which permits use, sharing, adaptation, distribution and reproduction in any medium or format, as long as you give appropriate credit to the original author(s) and the source, provide a link to the Creative Commons licence, and indicate if changes were made. The images or other third party material in this article are included in the article's Creative Commons licence, unless indicated otherwise in a credit line to the material. If material is not included in the article's Creative Commons licence and your intended use is not permitted by statutory regulation or exceeds the permitted use, you will need to obtain permission directly from the copyright holder. To view a copy of this licence, visit http://creativecommons.org/licenses/by/4.0/.

\section{References}

Barnabás B, Obert B, Kovács G (1999) Colchicine, an efficient genome-doubling agent for maize (Zea mays L.) microspores cultured in anthero. Plant Cell Rep 18:858-862

Battistelli GM, Von Pinho RG, Justus A, Couto EGO, Balestre M (2013) Production and identification of doubled haploids in tropical maize. Genet Mol Res 12(4):4230-4242

Belicuas PR, Guimarăes CT, Paiva LV, Duarte JM, Maluf WR, Paiva E (2007) Androgenetic haploids and SSR markers as tools for the development of tropical maize hybrids. Euphytica 156:95-102. https://doi.org/10.1007/s10681-007-9356-z

Chaikam V, Mahuku G (2012) Chromosome doubling of maternal haploids. In: Prasanna BM, Chaikam V, Mahuku G (eds) Doubled haploid technology in maize breeding: theory and practice. CIMMYT, Mexico, pp 24-29

Chaikam V, Prasanna BM (2012) Maternal haploid detection using anthocyanin markers. In: Prasanna BM, Chaikam V, Mahuku G (eds) Doubled haploid technology in maize breeding: theory and practice. CIMMYT, Mexico, pp 20-23

Chaikam V, Nair SK, Babu R, Martinez L, Tejomurtula J, Boddupalli PM (2015) Analysis of effectiveness of R1-nj anthocyanin marker for in vivo haploid identification in maize and molecular markers for predicting the inhibition of R1-nj expression. Theor Appl Genet 128:159-171

Chaikam V, Martinez L, Melchinger AE, Schipprack W, Prasanna BM (2016) Development and validation of red rootmarker-based haploid inducers in Maize. Crop Sci 56:1678-1688

Chaikam V, Lopez LA, Martinez L, Burgueno J, Boddupalli PM (2017) Identification of in vivo induced maternal haploids in maize using seedling traits. Euphytica 177:1-9. https://doi.org/10.1007/s1068 1-017-1968-3

Chaikam V, Molenaar W, Melchinger AE, Boddupalli PM (2019) Doubled haploid technology for line development in maize: technical advances and prospects. Theor Appl Genet 132(12):3227-3243. https://doi.org/10.1007/s00122-019-03433

Chase SS, Nanda DK (1956) Comparison of variability in inbred lines and monoploid-derived lines of maize (Zea mays L.). Crop Sci 5:275-276

Choe E, Carbonero CH, Mulvaney K, Rayburn AL, Mumm RH (2012) Improving in vivo maize doubled haploid production efficiency through early detection of false positives. Plant Breed 131:399-401

Coe EH (1959) A line of maize with high haploid frequency. Am Nat 93:381-382
Csetneki A (1967) In: Gyulavári O (ed) Methods for quicker breeding of valuable maize lines (in $\mathrm{Hu}$ ). Ph.D. thesis, Keszthely

Dang NC, Munsch M, Aulinger I, Renlai W, Stamp P (2012) Inducer line generated double haploid seeds for combined waxy and opaque 2 grain quality in subtropical maize (Zea mays L.). Euphytica 183:153-160

De Oliveira Couto EG, Resende Von Pinho EV, Von Pinho RG, Veiga AD, de Carvalho MR, de Oliveira Bustamante F, Nascimento MS (2015) Verification and characterization of chromosome duplication in haploid maize. Genet Mol Res 14(2):6999-7007

Dudits D, Török K, Cseri A, Paul K, Nagy AV, Nagy B, Sass L, Ferenc G, Vankova R, Dobrev P et al (2016) Response of organ structure and physiology to autotetraploidization in early development of energy willow. Plant Physiol 170:1504-1523. https://doi. org/10.1104/pp.15.01679

Gyulavári O (1967) Ph.D. thesis, entitled: Methods for quicker breeding of valuable maize lines (in $\mathrm{Hu}$ ). Keszthely

Hu H, Schrag TA, Peis R, Unterseer S, Schipprack W, Chen S, Lai J, Yan J, Prasanna BM, Nair SK et al (2016) The genetic basis of haploid induction in maize identified with a novel genome-wide association method. Genetics 202:1267-1276

Melchinger AE, Schipprack W, Würschum T, Chen S, Technow F (2013) Rapid and accurate identification of in vivo-induced haploid seeds based on oil content in maize. Sci Rep 3:2129

Melchinger AE, Schipprack W, Mi X, Mirdita V (2015) Oil content is superior to oil mass for identification of haploid seeds in maize produced with high-oil inducers. Crop Sci 55:188-195

Milani KF, Baleroni AG, Silva HA, Mendes-Bonato AB, Pinto RJB, Scapim CA (2016) Effectiveness of the R1-navajo embryo marker on sorting haploids in tropical maize germplasm. Maydica 61:8

Novák-Hajós M, Gyulavári O (2013) Autotetraploid kukoricahibridek kombinálódó-képessége. XIX. Növénynemesítési Tudományos Nap, p 39. (in Hungarian)

Prigge V, Xu X, Li L, Babu R, Chen S, Atlin GN, Melchinger AE (2012) New insights into the genetics of in vivo induction of maternal haploids, the backbone of doubled haploid technology in maize. Genetics 190:781-793

Röber FK, Gordillo GA, Geiger HH (2005) In vivo haploid induction in maize-performance of new inducers and significance of doubled haploid lines in hybrid breeding. Maydica 50(3):275-283

Rotarenco VA, Kirtoca IH, Jacota AG (2007) Possibility to identifying kernels with haploid embryo by oil content. Maize Genet Coop Newsl 81:11

Senior ML, Murphy JP, Goodman MM, Stuber CW (1998) Utility of SSRs for determining genetic similarities and relationships in maize using and agarose gel system. Crop Sci 38:1088-1098

Shehata AI, Al-Ghethar HA, Al-Homaidan AA (2009) Application of simple sequence repeat (SSR) markers for molecular diversity and heterozygosity analysis in maize inbred lines. Saudi J Biol Sci 16:57-62

Yu W, Birchler JA (2016) A green fluorescent protein-engineered haploid inducer line facilitates haploid mutant screens and doubled haploid breeding in maize. Mol Breed 36:1-12. https://doi. org/10.1007/s11032-015-0428-9

Zhang Z, Qiu F, Liu Y, Ma K, Li Z, Xu S (2008) Chromosome elimination and in vivo haploid production induced by Stock 6-derived inducer line in maize (Zea mays L.). Plant Cell Rep 27:1851-1860

Zhao X, Xu X, Xie H, Chen S, Jin W (2013) Fertilization and uniparental hromosome elimination during crosses with maize haploid inducers. Plant Physiol 163:721-731 